\title{
Proposing a Standard Template for Construction Site Layout: A Case Study of a Norwegian Contractor
}

\author{
Børge Sjøbakk and Lars Skjelstad \\ SINTEF Technology and Society, Industrial Management \\ P.O. Box 4760 Sluppen, N-7465 Trondheim, Norway \\ \{borge.sjobakk, lars.skjelstad\}@sintef.no
}

\begin{abstract}
Having an efficient construction site layout can significantly impact the productivity, cost and safety of a construction project. Construction site layout planning is therefore recognized as a critical step in construction planning by researchers. In literature this is often described as an optimization process where some objectives (e.g. safety, cost savings) are pursued within the constraints of the site and facilities requirements. Such models are usually complex and difficult for practitioners to apply, and usually result in each project having its unique site layout plan. The authors challenge this by proposing a standard layout template that can easily be utilized in planning of multiple construction sites. It is argued that each site should be treated as a factory and that similarity between sites should be pursued due to the nature of the construction industry. The template has been developed in collaboration with a Norwegian contractor, utilizing the action research approach.
\end{abstract}

Keywords: Construction site layout planning, standardization

\section{$1 \quad$ Introduction}

It is generally agreed that having an efficient site layout can significantly impact the productivity, cost and safety on construction sites [1]. Planning of a site layout involves identification of temporary facilities (TFs) needed to support construction activities, such as barracks, workstations and cranes, and appropriate positioning of the TFs within the boundaries of the construction site [2]. The site layout tries to meet multiple objectives, such as minimizing hazards, travel distance and material handling time and avoiding obstruction of flows of material, equipment and personnel [2,3]. Usually, all these objectives cannot be met at the same time, and since the early 1970s construction site planning has received much attention from researchers within mathematical optimization $[4,5]$. Since then a range of models have been developed to automatically generate optimal layouts for construction sites [6].

In spite of its importance, site layout planning has often been either overlooked or considered to be of less importance by practitioners [7]. Often, site layout objects are located on a first-come first-served basis at the sites [6]. When planned the layout is often determined in an ad hoc manner based on various factors, such as rules of

adfa, p. 1, 2011.

(C) Springer-Verlag Berlin Heidelberg 2011 
thumb, expertise, code of practice and previous experience [8]. Such methods have traditionally been preferred over advanced optimization models by practitioners due to their simplicity [2]. However, a consequence of such approaches is that the site layout is greatly impacted by the preferences of the person responsible for the design of the layout [2].

The authors take the stance that a tool to support practitioners in construction site layout planning should be easy to use, require a minimum of data and promote similarity between different construction sites. The construction site should be viewed as a production plant in that TFs are located in a predefined manner relative to each other, the building and the site. The layout should sufficiently incorporate concerns for travel distances, safety, etc. without requiring vast effort put into the pursuit of an optimal solution. Further, it should be recognizable for employees, vendors and other actors visiting the site to minimize the time used searching for equipment, goods and other facilities. This paper proposes such a tool in the form of a standard template for construction site layout. The template can be used by a contractor (or an architect) to rapidly establish the construction site layout in a consistent and recognizable way, and communicate the layout to relevant actors. It has been developed in close collaboration with a Norwegian contractor.

The remainder of the paper is structured as follows: First, the research method and case company are described. Thereafter, some theoretical background on the construction site layout problem is described. This is followed by a description of the proposed template, including how it was developed together with the case company. Finally, the paper is concluded.

\section{Case Description}

The research is carried out utilizing the actions research method. In action research, the researchers and the problem holder (in this case a Norwegian Contractor) collaborate in solving real life problems while they keep a research interest in mind [9]. This creates a mutual dependence on the researchers' and the problem holder's skills and competences, which in turn generates new knowledge for both parties [9]. The researchers and the problem holder are both partners in a three-year research project related to high performance work systems and efficient industrialized operations in project-based industries in Norway.

The problem holder is a contractor located in the middle of Norway. It mainly carries out construction within commercial building, public works (e.g. schools, culture centers, sports installations) and large-scale housing projects. The company has traditionally focused on carpentry; however, a few years ago it acquired a concrete work company from the same region. In large-scale projects with turnkey contracts the company collaborates with, and coordinates, a number of subcontractors within multiple disciplines, such as HVAC and electrical installation.

The company has developed some standard operating procedures based on lean construction. This is mainly concerned with the Last Planner methodology [10], where trade foremen set up realistic weekly work plans and explore inter-disciplinary 
dependencies through weekly work planning meetings while keeping the master schedule in mind. Further, the different trades work through the building in a predefined manner; each trade completes its work in a room or section, proceeds to the next one and is succeeded by another trade. This is carried out from the top to the bottom of the building to reduce spillage in completed areas. In this way, the different trades can work in parallel without getting in each other's' way.

When starting new projects, the company has traditionally operated with simplistic and static site layouts, if any, often suggested by the architect of the project. Often, the site layout has evolved in a more ad hoc manner, with the first trades at the site (usually concrete work) defining the site layout.

The contractor is often involved in several parallel projects, causing the company to man different sites simultaneously. The company organizes its workforce in several multidiscipline teams, with the size of the teams reflecting experiences with previous projects. For example, the company claims that teams of 6-12 people are optimal for completing the carpentering in an apartment. Yet, lack of material, vacations, injuries etc., necessitates that people move from one site to another from time to time, in order to keep all teams within the preferred size and all projects to meet their due date.

No matter how well planned a single project is, time is spent searching for materials, seeking information, accessing nearest waste-containers etc. Moving personnel between sites and having guest workers on site increases time spent on non-valueadding activities. The need for a standardized site layout was therefore raised by both workers and management.

\section{The Construction Site Layout Challenge}

Designing a good construction site layout is a challenging task. Available site space is often a limited resource [7], and the site topography and location of fixed facilities within the site often restrict the choice of layout [8]. Within these boundaries required temporary facilities (TFs) should be dimensioned and appropriately positioned in order to achieve smooth and low-cost flow of materials, people and equipment within the site while maintaining safety concerns $[2,3]$.

In establishing a construction site layout/utilization plan, numerous aspects should be addressed $[3,11,12]$ : the site boundary must be identified; required TFs need to be determined based on planned project activities; size needs and other constraints associated with each TF must be established; the relative position of each TF must be decided; and, the timing of the establishment and removal of the TFs during the project must be defined. In practice, however, the construction site layout is often determined on a first-come first serve basis [6], with the detailed site layout being left to the day-to-day scheduling of trade foremen and managers [8]. This can lead to decreased safety and productivity [6], with inappropriate locations often leading to relocation of TFs or extra material handling that could have been avoided [8]. This is especially the case when space is not a limited factor in projects and TFs are located randomly within the site boundaries [11]. According to [2], empirical evidence suggest that the layout is affected by: (1) the role of the person doing it; (2) a person's 
level of involvement with the project; (3) the personal relationships between individuals making layout decisions and their authority within the organization; (5) a single person choosing among alternative strategies depending on the project's nature.

As construction site layout is an exercise where multiple, often conflicting objectives are pursued within the restrictions of the construction site and project details, it has captured the interest of researchers within mathematical optimization for several decades $[4,5]$. Numerous models have been have been developed to automatically generate optimal layouts for construction sites [6]. The earliest construction site layout planning (CSLP) models generated static layouts spanning the entire project duration [4], whereas more recent models typically incorporate concerns for changes over the duration of the construction projects. These are often denoted dynamic site layout planning (DSLP) models to distinguish them from static CSLP models [3,6].

From a research point of view, there are several challenges associated with existing construction site layout models [13]: there is an overweight of static CSLP models; FTs are treated as rectangular blocks (denoted equal-area CSLP models); most of the CSLP research concentrates on improving various optimization algorithms instead of establishing how to select the best out of proposed layouts; and, many models are single-objective optimization (SOO) models that fail to incorporate concerns for multiple layout objectives. From practitioners' view, there are several practical shortcomings of these models that make them prefer simple and well-understood models [2]: expertise is required for selecting an appropriate model and formulating each layout problem; the models require a substantial amount of data as input; the models are uneasy to use and alter; and, when substantial simplification is introduced in order to use a model, the results from it may be difficult to interpret.

From the authors' point of view, a large shortcoming of existing models is that they result in each construction project having its own unique site layout [14]. Arguably, the actors on site will be able to move most easily, quickly and safely within the site when the site layout in some way is standardized and recognizable. This especially applies for contractors with several parallel and sequential projects, which are able to reap learning effects from each project and apply in the others. As is evident, tools to support efficient construction site layout design must also be easy and fast to use, in order for practitioners to adapt them. In the next section, such a tool is proposed.

\section{$4 \quad$ Proposing a Template for Construction Site Layout}

A lot of research is done within the field of site optimization and lean construction. Still we find that many site optimization methods are too comprehensive to be carried out in construction firms, and also they often rely on a lot of input that is not available with sufficient precision at the time needed. Lean construction has provided valuable input on planning, whilst site layout, 5S, Poka-Yoke and waste in general still needs to be implemented to a larger degree. The proposed model opens for such activities.

Considering aspects that need to be addressed when designing the site layout as a starting point, the following steps were followed in order to develop a standardized site layout to be used as a template for future site layout planning: (1) Identification of 
temporary facilities (TFs) that should be included in the site layout; (2) establishment of reciprocity between facilities through a closeness rating analysis (CRA); (3) use of the CRA to establish site areas; (4) establishment of relationships between building and site ambit, as well as reciprocal distances between the different areas on site; (5) mapping of the different areas in a generic construction site template. With respect to the latter, the main side of the site, normally the one with road access, was defined and denoted side A. Further, sides B and C, which are secondary in terms of access, were also defined. On large building sites, these sides are often available. Finally, it was decided what must be located on side A, and what might be located on sides B and $\mathrm{C}$ (and even D) due to lack of space, improved access to building, or due to different project phases on different sides of a large building.

The TFs include all equipment and locations needed during the construction period. In collaboration with the case company, the following TFs were identified: walkway; barracks; tower crane; power supply; equipment containers; waste containers; entry/exit; material receipt; area for return of goods; inventory; workstation for masonry; parking/area for emergency vehicles; traffic artery; workstation for plumbing; workstations for others; and, the main entrance of the building. In addition the site might have areas that are not available due to preparation for gardens, parking lots etc., that also is expected to be completed alongside the building itself. These areas are simply considered not available for TFs.

A closeness rating analysis (CRA) was carried out to identify TFs' reciprocal dependencies (Fig 1). This is a way of rating layout objects against each other with respect to closeness importance, based on considerations such as frequency of interaction and safety concerns. The rating itself is a matter of team-work. Managers, skilled workers and researchers discussed each intersection in the matrix to get a balanced and compromised first solution. Of course, if experiences over time show disadvantages with the chosen solution, this first designed solution is subject to adjustments. Still, it represents a well-funded first setup. The input to the analysis was derived during a 3 hour meeting including sharing of experiences and theory, and discussion before decision.

When going through the results of the analysis, some groups of TFs materialized due to their similar score/pattern in the CRA: (1) material handling (material receipt, inventory and area for return of goods); (2) barracks (barracks and parking/emergency vehicles); (3) work stations (workstations masonry, plumbing and others); (4) lift (tower crane); (5) transportation (entry/exit and traffic artery); (6) waste (waste containers); and (7) equipment (equipment containers). By grouping the TFs in such a manner made the analysis more manageable in that it simplified the task and created a sense of overview. As power supply and walkways are needed on multiple locations, it was decided to leave them out of the analysis and rather draw these up where and when needed. 


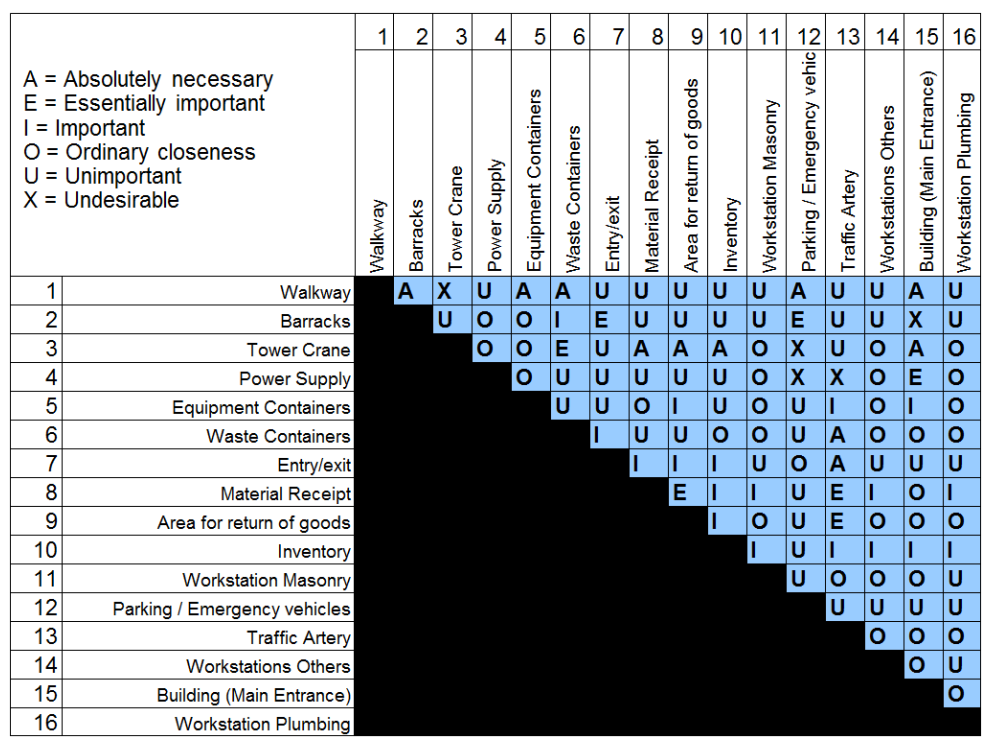

Fig. 1. Closeness Rating Analysis for Construction Site Facilities

The next step was to determine how these groups could be distributed over the available site. In doing so, the researchers established a priority chart showing the relationships between the groups of TFs and the distance from the building to the site ambit (Fig. 2).

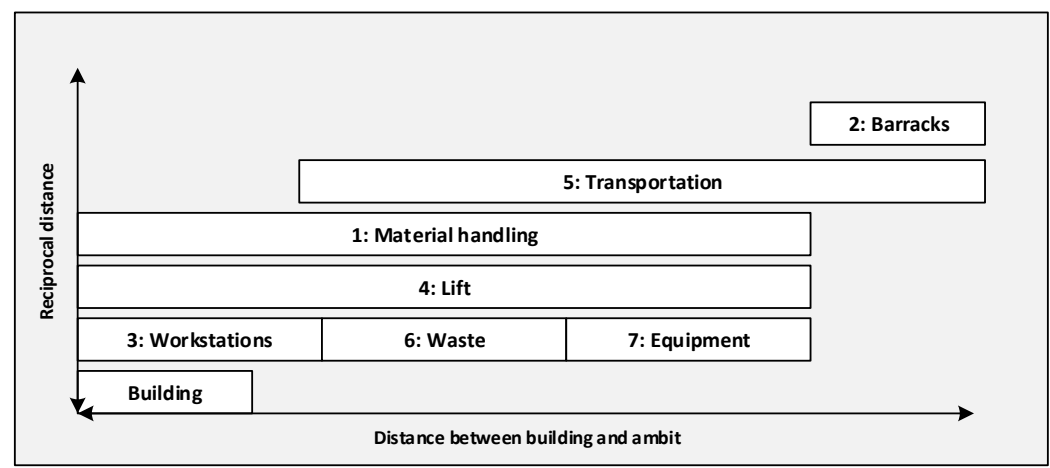

Fig. 2. Priority Chart

The next step was to transfer this into a schematic illustration of a construction site, resulting in the proposed template. This was done by analyzing the CRA and the priority chart, and coming up with additional requirements to the layout. For example, the building must be accessible from all sides in terms of a walkway. Further, it is not desirable to spread over multiple sides of the building if there is sufficient space on one side. The traffic artery should force one-directional traffic flow. Power supply 
need to be a grid on big sites, preferably with access from all sides of the building. Waste-bin access is as important as position of input material. Safety in terms of access to a defined spot with vehicles must not be compromised. Cranes also play an important role in emergency situations if available in the situation. The learnings could then be used to draw a number of possible layouts, from which the project team jointly had to identify the preferred alternative.

Our case-company landed on the layout shown in Fig. 3. If possible, it is considered an advantage with all facilities on one side. This presupposes that cranes can cover both building and the "factory side area". If not, multiple sides should be considered for the site layout. The work therefore also identified what facilities and areas to be moved out to sides $\mathrm{B}$ and $\mathrm{C}$ in terms of a priority list.

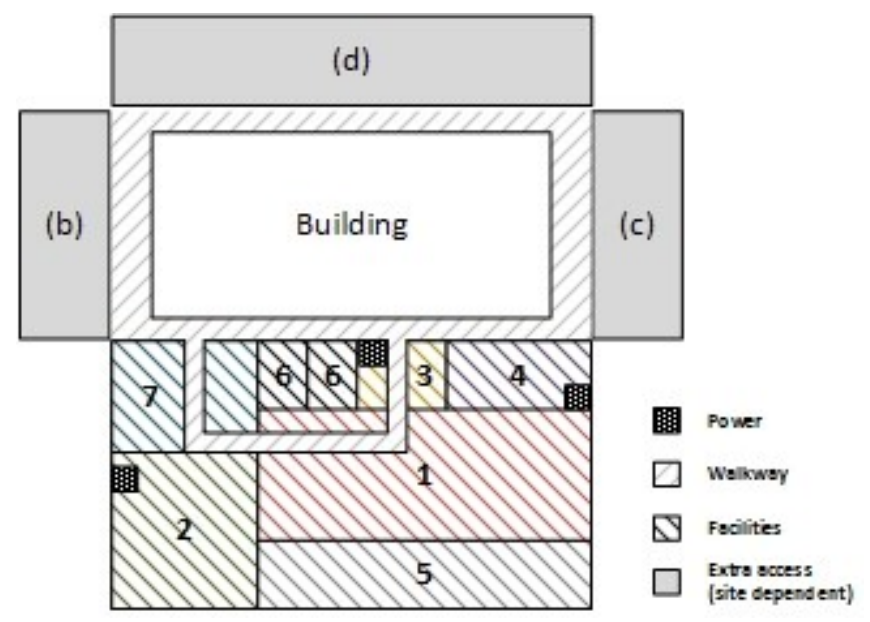

Fig. 3. Template for Construction Site Layout at Norwegian Contractor

\section{Conclusion}

The constructor has implemented the new site layout and introduced it in the company as its way to arrange facilities. The project presented a doable solution for site arrangement which was developed together with the company. This increases the possibility for it to be used on a regular basis. At all construction sites a lot of time is spent on searching for materials and tools, and we suggest that this waste is reduced with the suggested model. After experience is gained, adjustments to the first developed layout can be made. A learning curve is expected as the solution is repeated a number of times. Also, between projects similarities allow for easier transfer of people according to needed progress without sacrificing too much time on getting acquainted with the new site. Management should repeat the exercise for different project phases, to build a library of standardized solutions to cover necessary dynamics into the practical solution. The method itself should be part of the company's project execution model. Its simplicity increases its applicability. 
A lot of research is done within the field of site optimization and lean construction. Still we find that many site optimization methods are too comprehensive to be carried out in construction firms. Often, they rely on a lot of input that is not available with sufficient precision at the time needed. Lean construction has provided valuable input on planning, whilst site layout, 5S, Poka-Yoke and waste in general still needs to be implemented to a larger degree. The proposed model opens for such activities.

Acknowledgements. This work has been conducted within the project HPWS.no funded by the Research Council of Norway. The authors would like to thank the participants of the projects for providing valuable empirical data.

\section{References}

1. El-Rayes K, Khalafallah A (2005) Trade-off between safety and cost in planning construction site layouts. J Constr Eng M ASCE 131 (11):1186-1195

2. Tommelein ID, Levitt R, Hayes-Roth B (1992) Site-layout modeling: How can artificial intelligence help? J Constr Eng M ASCE 118 (3):594-611

3. Elbeltagi E, Hegazy T, Eldosouky A (2004) Dynamic layout of construction temporary facilities considering safety. J Constr Eng M ASCE 130 (4):534-541

4. Elbeltagi E, Hegazy T, Hosny AH, Eldosouky A (2001) Schedule-dependent evolution of site layout planning. Constr Manage Econ 19 (7):689-697

5. Isaac M, Andayesh F, Sadeghpour A A comparative study of layout planning problems. In: Hajdu M, Skibniewski MJ (eds) Creative Construction Conference, Budapest, Hungary, 2012. Diamond Congress Ltd., Budapest, pp 272-282

6. Andayesh M, Sadeghpour F (2013) Dynamic site layout planning through minimization of total potential energy. Automation in Construction 31:92-102

7. Tommelein I, Zouein P (1993) Interactive dynamic layout planning. J Constr Eng M ASCE 119 (2):266-287

8. Chau K, Anson M (2002) A knowledge-based system for construction site level facilities layout. In: Developments in Applied Artificial Intelligence. pp 393-402

9. Greenwood DJ, Levin M (2007) Introduction to action research : social research for social change. Thousand Oaks, California, Sage

10. Ballard HG (2000) The last planner system of production control. The University of Birmingham,

11. Mawdesley MJ, Al-Jibouri SH, Yang H (2002) Genetic algorithms for construction site layout in project planning. J Constr Eng M ASCE 128 (5):418-426

12. Zouein P, Harmanani H, Hajar A (2002) Genetic algorithm for solving site layout problem with unequal-size and constrained facilities. J Comp Civil Eng 16 (2):143151

13. Ning X, Lam K-C, Lam MC-K (2011) A decision-making system for construction site layout planning. Automation in Construction 20 (4):459-473

14. Zolfagharian S, Irizarry J Current Trends in Construction Site Layout Planning. In: Construction Research Congress 2014@ sConstruction in a Global Network. ASCE, pp 1723-1732 